\title{
Effect of Soil Texture on Remediation of Hydrocarbons-Contaminated Soil at El-Minia District, Upper Egypt
}

\author{
Th. Abdel-Moghny, ${ }^{1}$ Ramadan S. A. Mohamed, ${ }^{2}$ E. El-Sayed, ${ }^{2}$ \\ Shoukry Mohammed Aly, ${ }^{3}$ and Moustafa Gamal Snousy ${ }^{2}$ \\ ${ }^{1}$ Applications Department, Egyptian Petroleum Research Institute, Ahmed El-Zomer, Nasr City, P.O. Box 11727, Cairo, Egypt \\ ${ }^{2}$ Geology Department, Faculty of Science, El-Minia University, P.O. Box 61519, El-Minia, Egypt \\ ${ }^{3}$ Petrotreat Co., Egypt \\ Correspondence should be addressed to Th. Abdel-Moghny, thanaa_h@yahoo.com
}

Received 20 February 2012; Accepted 8 May 2012

Academic Editors: A. Mittal, A. M. Seayad, and A. Szymczyk

Copyright (C) 2012 Th. Abdel-Moghny et al. This is an open access article distributed under the Creative Commons Attribution License, which permits unrestricted use, distribution, and reproduction in any medium, provided the original work is properly cited.

\begin{abstract}
Soils polluted by waste lubricant oils may affect the hydrosphere compromising the quality of drinking water resources and threatening the aquatic ecosystems. The objective of this study focused to remove waste-lubricant oils from different polluted sites in El-Minia governorate. In this respect some samples were collected from four different industrial sites and identified as sand, loamy sand, clay loam and loam. Then the field conditions were simulates using two experimental models packed with contaminated soil. The remediation processes carried out in both models using surfactant enhanced by air injection then by water washing. The parameters such as soil type, soil heterogeneity, time and washing process was investigated. The results indicated that the high efficiency of oil removal is obtained from sand where the clay loam gives the worst results. The results also reveal that, the high flushing and washing duration time can be attributed to the high percentage of mud in some sites over other sites. This means that the performance of surfactant flushing/water washing can be adversely affected by geologic heterogeneity. Finally, it's suitable to use pressurized liquid technologies in heterogeneous media, but cleanup times will be longer and more difficult than for the other similar homogeneous media.
\end{abstract}

\section{Introduction}

Throughout the world, subsurface contamination has become a widespread and pervasive problem. A major problem in the soil or groundwater remediation is the removal of hydrophobic organic compounds. Nonaqueous phase liquids (NAPLs) usually enter the unsaturated zone as discrete liquid phases, which move due to gravitational and capillary forces [1]. They frequently enter groundwater systems after they have been spilled on the surface and pass through the unsaturated zone (Figure 1). The major organic chemical waste categories include organic aqueous waste (e.g., pesticides), organic liquids (e.g., chlorinated solvents), oils (e.g., different fuels and fuel additives), and sludges or solids containing organic compounds. The most common local source of soil and water contamination by petroleum hydrocarbons are industrial plants, land disposal sites of danger residues, petrol stations, car service stations, and vehicle accidents. The total petroleum hydrocarbons include saturated alkanes, aromatic hydrocarbons, fuel oxygenated additives (e.g., methyl t-butyl ether (MTBE), ethanol, butanol), and other compounds containing sulfur or nitrogen. These compounds are harmful or even toxic to the growth and development of plants and animals, being a source of long-term water and air pollution. They are also dangerous to the human health [2]. Accidental surface release and improper disposal of petroleum products (e.g., jet fuel, refinery wastes, diesel, lubricating used oil, etc.) and volatile organic solvents are recognised as two of the most widespread causes of groundwater contamination by chemical compounds. Flooding and/or accidents, oil from the waste pit may spread to the surrounding fields causing pollution [3]. 


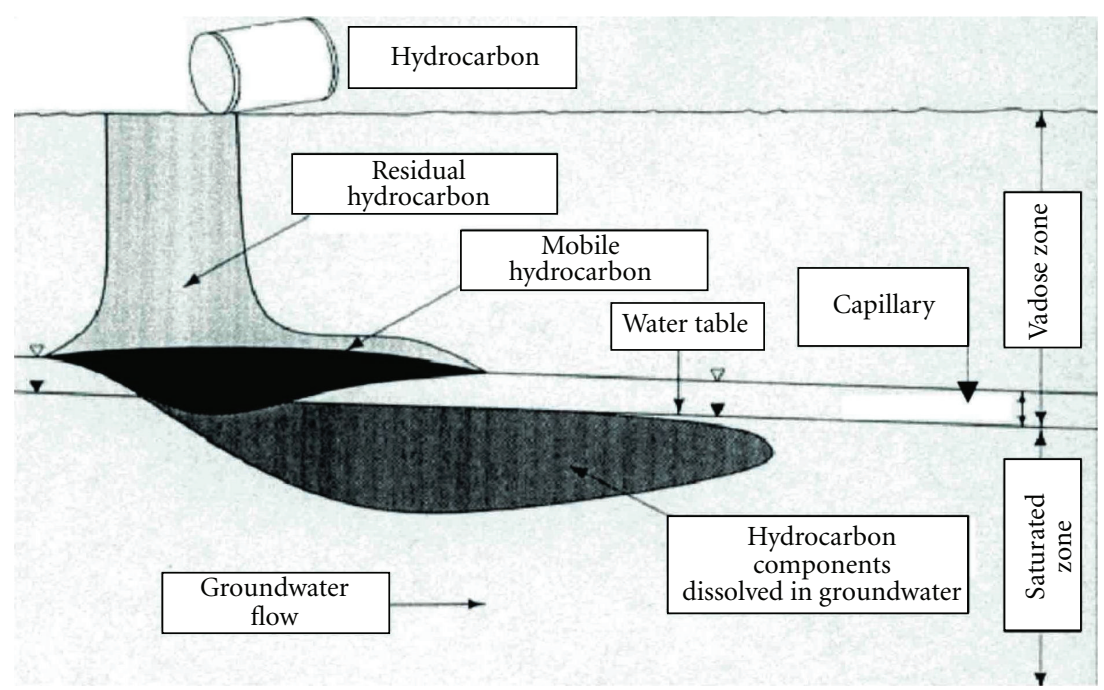

FIGURE 1: Illustration of the subsurface distribution of an NAPL spill [4].

Nonaqueous phase liquids (NAPLs) that are less dense than water, including many petroleum products or fuels, such as gasoline, heating oil, lubricating oil, kerosene, jet fuel, and aviation gas, are termed light nonaqueous phase liquids (LNAPLs) and these commonly collect and pool at, or above, the water table. The other type of NAPL is denser than water and named dens nonaqueous phase liquids (DNAPLs) include chlorinated hydrocarbons or chlorohydrocarbon such as carbon tetrachloride, 1,1,1trichloroethane, chlorophenols, chlorobenzenes, tetrachloroethylene, and polychlorobiphenyls (PCBs). The latter are thus particularly difficult to remediate [5]. Matters become even more complicated since these contaminants are often mixed with metals. A considerable amount of hydrocarbon oils can be held in voids in the soil in the form of residual saturation and can lead to long-term contamination of groundwater through the action of rain water, if not removed in time [6]. During the transportation of NAPLs through the subsurface, a portion of the organic phase also retained within the pores of the soil matrix as an immobile ganglia or globules due to interfacial forces.

Physical Properties of Soil. The procedure selected to contain spills on land will vary with the amount and type of oil spilled, the type of soil, and the terrain. Less viscous oil and more porous soil will allow greater and more rapid penetration and lateral migration in the soil. Groundwater is very susceptible to contamination, unless protected by a low permeability layer such as clay. The organic contaminants like petroleum hydrocarbons, halogenated organic compounds, or other organic compounds are bind strongly inside the soil matrix and present for long time at the contaminated sites. Knowledge of physical properties of soil is most important for designing the parameters of remediation process. The mechanisms of interaction between the soil and contaminants are also important to know. Soil can be defined as loose material composed of weathered rock, other minerals, and also partly decayed organic matter, that covers large parts of the land surface [7]. The soil is composed of three phases: solid, liquid, and gas phases. The soil components include about $50 \%$ by volume mineral particles, 25\% water, 20\% air, and 5\% organic matter. With the exception of a few organic soils, the bulk of soil material is mineral in character and has been derived from solid geological deposits [8]. The mineral constituents of the soil are represented by the particles of widely varying size, shape, and chemical composition. Three groupings of soil particles are in common use, namely, sand, silt, and clay. The groups are subdivided according to requirements.

Long-Term Contamination. The NAPL that remains in the unsaturated zone is an important source of contamination because it is dissolved by (1) the passing recharge water and (2) the passing groundwater as the water table rises. Such sources of contamination can last for many years and contaminate large volumes of groundwater. However, in addition to these pathways, contaminants also can be transported through the unsaturated zone. This transport pathway may spread the contaminants over a much broader area of the aquifer. In recent years, there has been an increasing interest in the remediation of NAPLs source zones [9]. Because of the low solubility of hydrophobic organic compounds in water, the residual organic phase usually represents a longterm contamination source for soil and groundwater. Owing to the tendency of contaminants to tightly bind or absorb onto the soil particles. Subsurface contamination by the organic compounds is a complex process and difficult to treat due to many reasons like the tendency of adsorption of contaminants onto the soil matrix, low water solubility, and limited rate of mass transfer for biodegradation, and so on [10]. As many organic compounds have low solubility in water, so they may leach from the soil for a longer period of time and thus ultimately become a continuous source of the soil and groundwater contamination. The use of surfactants can improve the mobility of hydrocarbon contaminants in soil-water systems by solubilising adsorbed hydrocarbons through incorporation in surfactant micelles [11]. 
This work aims to remove NAPL (waste-lubricant oils) polluted soils and collected from different industrial sites in El-Minia governorate. The air flushing as distributive system enhanced by surfactant and different water flooding cycles were used in this study. Two models were designed to simulate the injection wells and treatment tanks. Nonionic surfactant solutions Nonyl phenol ethoxylate ( $\left.\mathrm{NPEO}_{9}\right)$ were used at constant concentrations (3\%) beyond its critical micelle concentration. The results discussed based on soil heterogeneity to select the suitable remedial techniques (in situ or ex situ).

1.1. Samples Locations. The design of optimal remediation schemes often requires some "prediction" of the distribution of contaminants within the subsurface over time. These predictions can be used to evaluate different remediation scenarios. Two-dimensional random sampling designs commonly exist for contamination sampling over space [12]. According to Jessen [13] which proposed high accuracy can be improved by better sampling and procedures, so samples collected with low bias and high precision from the centre of contamination zone.

1.2. Soil Sampling and Site Assessment. Determining the extent and spatial distribution of NAPL ensures that the chemical flood targets the proper subsurface volume. There are many techniques that investigators have used to map NAPL distribution. Perhaps the most precise and appropriate parameter to measure characterizing an NAPL source zone is saturation.

Saturation is defined as the fraction of the soil pore volume that is filled with NAPL. Depending on the degree of saturation, NAPL will exist as either free-phase NAPL or as residual NAPL. Free-phase or mobile NAPL exists when the saturation is high enough to form pore-to-pore connections over a large area, producing a continuous fluid capable of flowing under an imposed gradient or its own gravitational potential. Residual or entrapped NAPL exists when the soil pores have been drained of mobile NAPL, leaving behind some amount of liquid trapped by capillary forces or the surface tension that holds a liquid to a solid surface. NAPL at residual saturation is discontinuous and immobile, unable to flow under normally imposed hydraulic gradients.

A sampling technique was developed for allowing the decision makers to determine the minimum number of field realizations necessary to achieve a reliable remediation design [14]. This section provides collecting and analyzing soil samples from the NAPL zone. Soil samples can be used to provide an estimate of how NAPL is distributed in the source zone by providing contaminant concentration data that can be converted to saturation estimates. Soil samples also provide an indication of the vertical heterogeneity in the zone of interest. Laboratory analyses will yield a measurement of the total concentration in the soil samples. Soil samples are also collected to measure grain-size distribution, and the fraction of organic contaminant of the geologic media. Grain-size analyses are used to define heterogeneity and point permeabilities in the subsurface and should be collected at a
TABLe 1: Physical properties of the used lubricating oil.

\begin{tabular}{lc}
\hline Specific gravity at $20^{\circ} \mathrm{C}$ & 0.875 \\
Flash point, close cup Pensesky Martin $\left({ }^{\circ} \mathrm{C}\right)$ & 140 \\
Water and sediment (vol\%) & 1.28 \\
Water content, the Dean and Stark method (vol\%) & 0.79 \\
Viscosity at $37.8^{\circ} \mathrm{C}, \mathrm{cst}$ & 209.235 \\
Ash content $(\mathrm{wt} \%)$ & 0.714 \\
Asphaltene content $(\mathrm{wt} \%)$ & 4.995 \\
\hline
\end{tabular}

frequency sufficient to define the major hydrostratigraphic units in the NAPL zone [15].

Representative soil samples were collected from different locations: (A) Helwan cement Co. El-Minia factory site, (B) PEPSI Cola El-Minia factory site, (C) Egyptian Co. for productive Electricity site, and (D) Middle Egypt Mills Co. site, as shown in the map Figure 2, and the lithological succession shown in Figure 3. In the selected sites, the contaminant (waste lubricant oils) distribution on the surface was observed to be inconsistent. Visual observation and random estimates of the oil content indicated variety of infiltration rates up to a depth of $40 \mathrm{~cm}$. Accordingly, three samples, weighing $1 \mathrm{~kg}$ each, were collected from different depths going upto a maximum of $40 \mathrm{~cm}$ from the top layer beneath the ground surface [16]. Samples were stored in plastic buckets and homogenised in a mixer and it was airdried for 3 days before selecting a sample for analysis and cleaned for sieving [17]. Size classification was achieved by sieving into gravel, medium, coarse, fine, and very fine sand also silt + clay fractions.

\section{Materials and Methods}

\subsection{Materials}

(1) Commercial nonionic surfactant nonyl phenol ethoxylate $\left(\mathrm{NPEO}_{9.3}\right)$ was used without treatment.

(2) The $n$-hexane used for extraction step was obtained as analytical grade solvent of used oil from the soil.

(3) Polluted soils from different sites in El-Minia governorate were collected to study the actuality of contamination problem and efficacy of treatment trains. Physical properties of the used lubricating oil are given in Table 1.

2.2. Experimental Setup. The actual contamination field conditions is simulate and designed in two experimental setup models and as shown in Figures 4 and 5. The downflow mode was applied in this experiment.

\subsection{System Operation}

2.3.1. First Laboratory Model. The first lab model simulate injection well was consisted of a cylindrical column having dimensions $(105 \mathrm{~cm} \times 5 \mathrm{~cm} \times 4.5 \mathrm{~cm})$ caped with a stainless steel valve top. The outlet end of the column was fitted with a fine wire mesh screens ( $50 \mu \mathrm{m}$ diameter) to prevent soil 


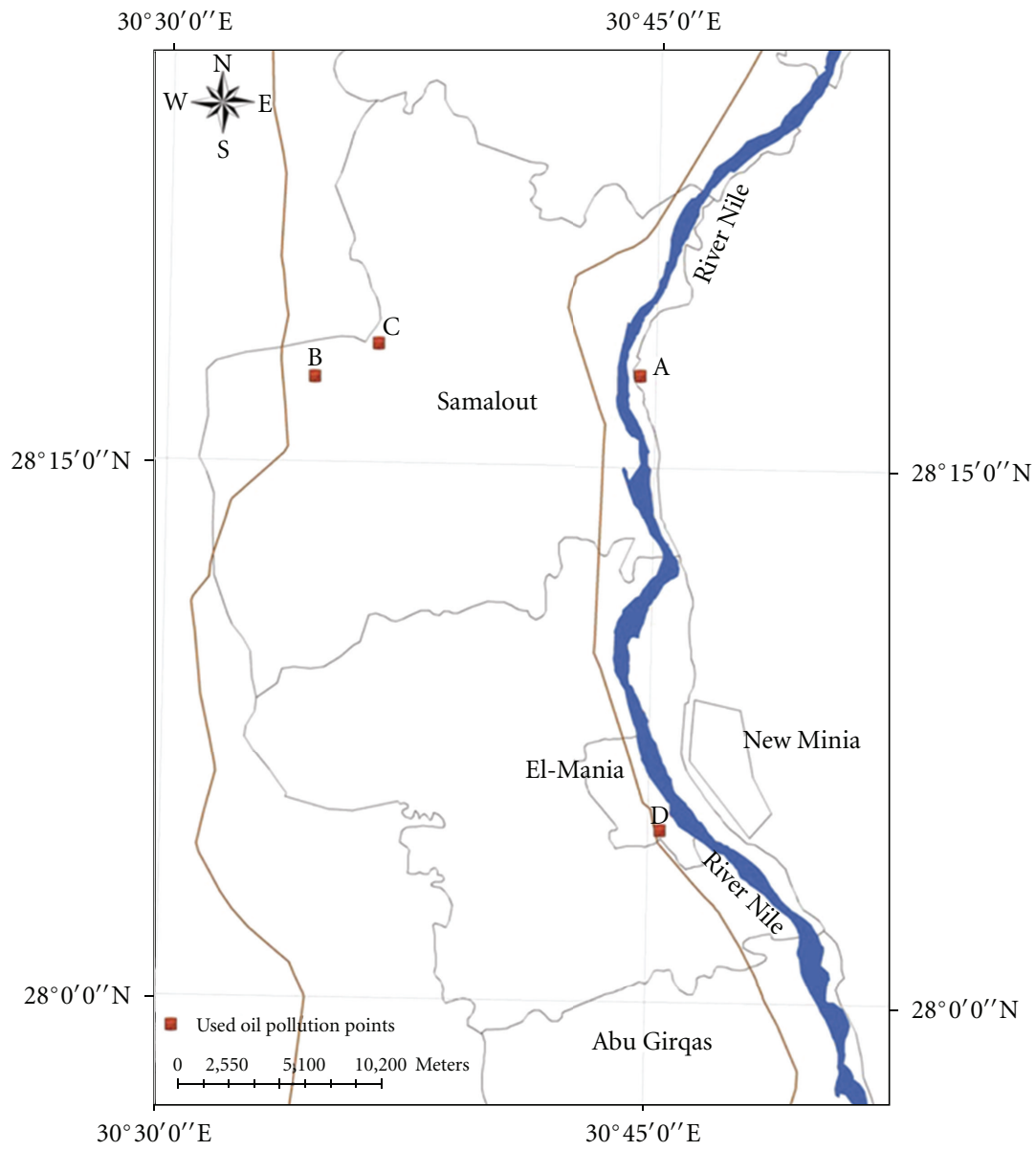

FIGURE 2: Location map of some oil polluted sits in Minia governorate.

from washed out, then $31 \mathrm{~cm}$ of contaminated soil $(1 \mathrm{~kg})$ was packed in the column filled with surfactant solution to avoid entrapped air. After that the air was injected using air compressor to provide air and to pump surfactant solution and water across contaminated soil. The air was inlet from the side of the column to create turbulent air current, to provide better distribution of the injected air with similar and strong focusing at all points of soil surface. Air-flushing systems operated by pulsed mode (i.e., turning the system on and off at specified intervals), the pulsed air (cyclical) injection intermittently is thought to achieve more extensive, better distribution, and mixing of the air in the contaminated saturated zone, thereby allowing greater contact with the dissolved phase contaminants [19]. A fixed $300 \mathrm{~mL}$ of nonyl phenol ethoxyl $\left(\mathrm{NPEO}_{9.3}\right)$ surfactant solution of 3, 5 and $7 \%$ concentrations were injected individually at constant (2 bars) air pressure into different polluted field samples having concentrations of $2.55 \%, 12.7 \%, 5.8 \%$, and $4.37 \%$ for loamy sand (site A), sand (site B), loam (site C), and clay loam (site D), respectively.

2.3.2. Second Lab Model. The second lab model simulates treatment tank were designed to remediate field samples of sites $\mathrm{C}$ and $\mathrm{D}$ because they contain high percent of silt and clay respectively. The treatment tank consisted of bottle having dimension $(37 \mathrm{~cm} \times 15.5 \mathrm{~cm} \times 15 \mathrm{~cm})$. The pores membrane was located below the half of bottle and covered with a fine nylon mesh screens $(60 \mu \mathrm{m}$ diameter $)$ to prevent emulsion formation due to presence of silt and clay having very small grain size range and to facilitate of their washing out during the experimental work. Then $31 \mathrm{~cm}$ of contaminated soil $(1 \mathrm{~kg})$ was packed in the bottle. After that the air was injected using air compressor with a pressure not reach to 2 bar. Each samples were stirred with water after surfactant was washing out and then subjected to air pressure at 1.5 bar for two minutes, this step was repeated twice using 4 liters of water to wash out silt or clay that restrict air injection, emulsion extraction, and treatment process.

2.4. Treatment of Contaminated Soils. For all experiments the treatment of contaminated soils was carried out in two steps: flushing with surfactant solution then washing by many polishing cycles of water. The effluent samples were collected in a beaker and kept at room temperature for analysis, also soil was taken after each run to evaluate the percentage of waste oil remaining in the soil after each run.

2.5. Determining Oil Removal. $n$-hexane $\left(\mathrm{C}_{6} \mathrm{H}_{14}\right)$ was used to extract the waste oil as herein after by Khalladi et al. [20] and Marek et al. [21]. 


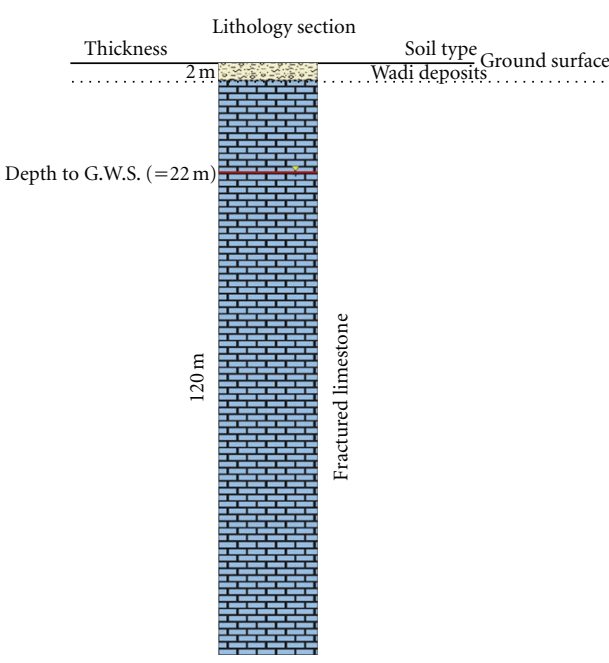

(a)

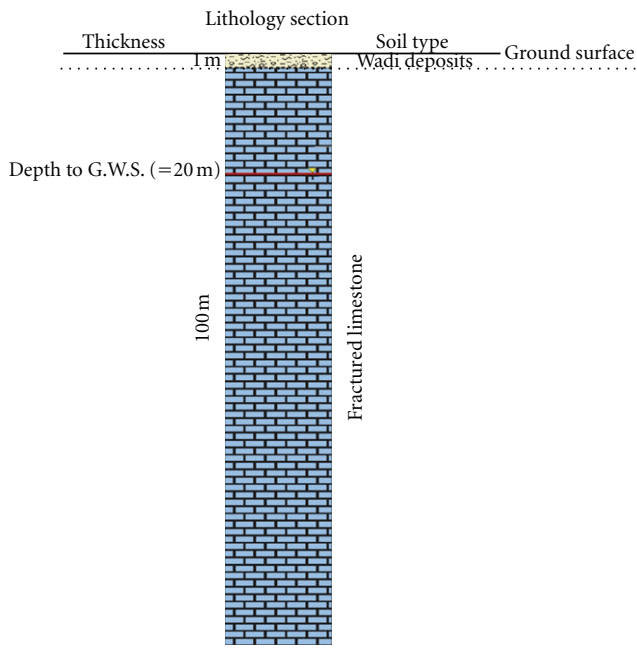

(c)

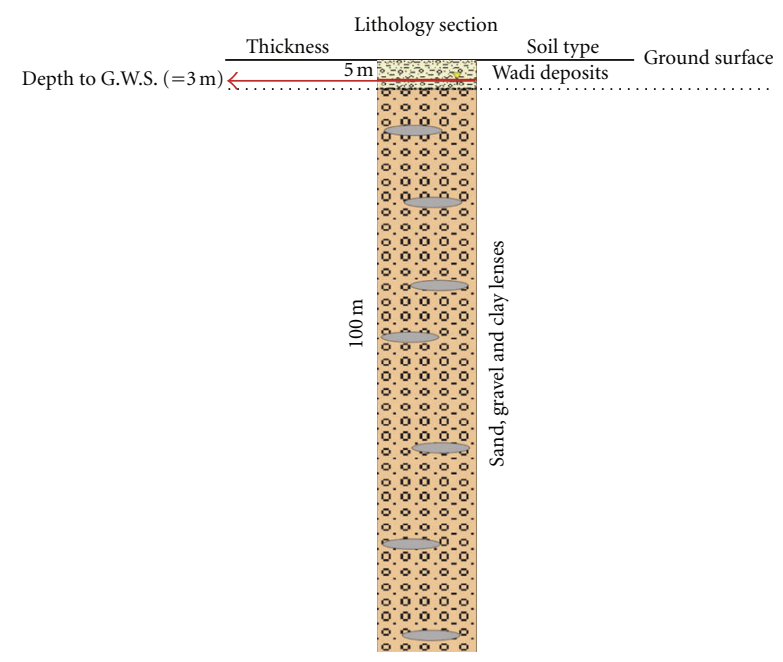

(b)

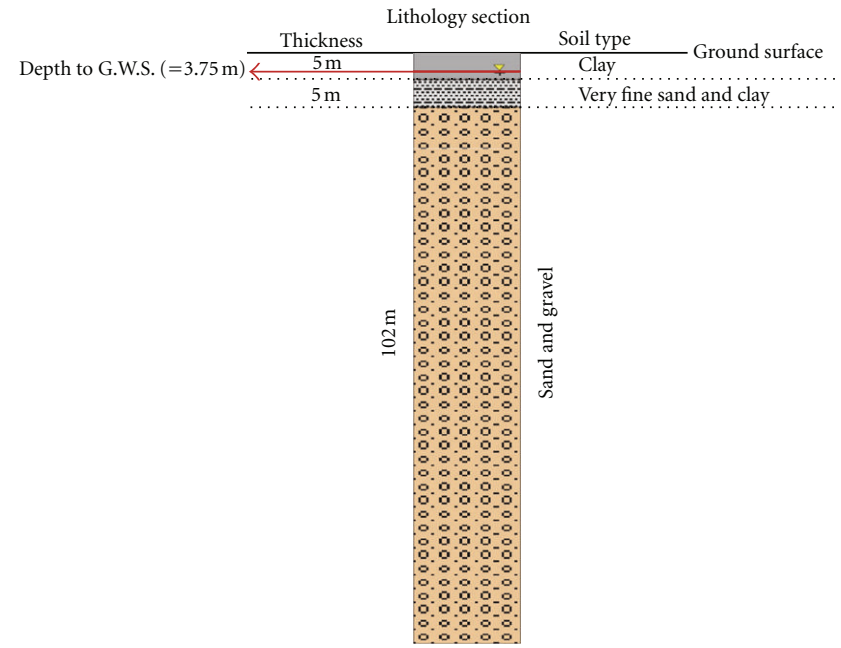

(d)

Figure 3: Lithology section of the investigated area [18].

2.6. Extraction and Analysis. Samples under distinct extractions: oil in soil phases and oil in water phases.

Oil in Soil. $2 \mathrm{~g}$ of rinsed soil were mixed with $10 \mathrm{~mL}$ of $n$ hexane in a glass test tube and shaken laterally for $5 \mathrm{~min}$ then left at rest for separation, then the $n$-hexane/oil extract was removed and the mixture was poured in a beaker. Each rinsed soil was washing four times to ensure completely clean from residual oil, this process was repeated till the extract gave the same absorbance reading as a pure $n$-hexane (zero absorbance) by using ultra violet spectroscopy.

Oil in Water (Emulsion). The remaining pollutant concentration was determined after stopping the water washing cycles. $5 \mathrm{~mL}$ of liquid effluent (oil-in-water emulsion) were collected and mixed with $25 \mathrm{~mL}$ of $n$-hexane in a separating funnel; stirred for $2 \mathrm{~min}$ then left at rest for separation; the upper organic layer was separated by using separating funnel.

\section{Results and Discussion}

We need to define the vertical and lateral extent of contamination in soil to determine if active remediation is necessary (i.e., if in situ action will take place, and if so, to what degree). From there, the vertical and lateral extent of contamination must be delineated to a level that is at or below the subsurface soil risk-based screening level.

3.1. Measuring Pollutant Concentrations. For many industrial sites, pollutant concentrations are highly variable, especially if the pollutants are immobile and there are multiple phases of polluting activity. It is known that the procedure selected to inhibit spills on land will greatly vary with the amount and type of oil spilled also with the type of soil and the terrain. Less viscous oil and more porous soil will allow greater and more rapid penetration and lateral migration in the soil.

To verify that the polluted soil is not contaminated above acceptable limits, confirmatory samples (discreet) will be 
TABLE 2: Waste lubricant oil concentrations in soil samples from A, B, C, and D sites.

\begin{tabular}{|c|c|c|c|c|c|}
\hline Samples locations & Samples Classification & $\begin{array}{c}\text { Waste oil } \\
\text { concentrations from } \\
0-10 \mathrm{~cm}(\mathrm{~g} / \mathrm{kg})\end{array}$ & $\begin{array}{c}\text { Waste oil } \\
\text { concentrations from } \\
10-20 \mathrm{~cm}(\mathrm{~g} / \mathrm{kg})\end{array}$ & $\begin{array}{c}\text { Waste oil } \\
\text { concentrations from } \\
20-40 \mathrm{~cm}(\mathrm{~g} / \mathrm{kg})\end{array}$ & $\begin{array}{c}\text { Average waste oil } \\
\text { concentrations }(\mathrm{g} / \mathrm{kg})\end{array}$ \\
\hline Site A & Loamy sand & 35.70 & 22.67 & 18.14 & 25.50 \\
\hline Site B & Sand & 130 & 125.58 & 125.58 & 127.05 \\
\hline Site C & Loam & 60.32 & 58.64 & 55.29 & 58.08 \\
\hline Site D & Clay loam & 52.96 & 43.51 & 31.73 & 42.73 \\
\hline
\end{tabular}

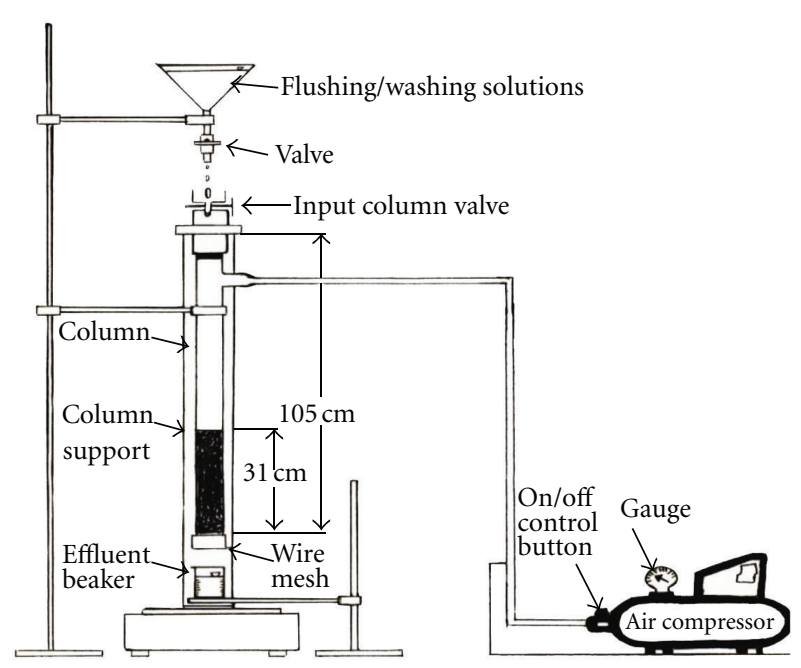

(a)

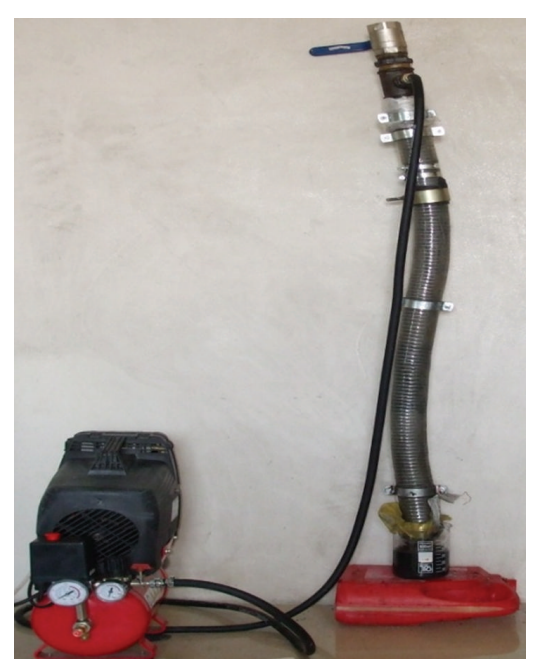

(b)

FIGURE 4: The laboratory experimental model simulates injection well.

taking from different sites A, B, C, and D. The soil samples are selected according to [22] who state that it is up to you to determine how many soil samples are needed to be representative of the conditions remaining in the site.

The contaminated soils were selected by choosing four different location sites. Each site samples were taken separately from different depths ( 0 up to $40 \mathrm{~cm}$ ). The proportion percentage of oil in each depth was then determined and added together and their average were taken and consider as representative sample for each site and defined by average waste oil concentration, and the samples analyzed based on our knowledge of waste lubricant oil and initial sample results are given in Table 2.

The results in Table 2 indicate that the average residual oil concentrations in contaminated site A, C, and D caused by movement of oil mobile phase (free phase) and thus their concentrations in the soil are not homogeneous, and recorded the following values $2.5 \%, 5.8 \%$, and $4.2 \%$, respectively. Also the pollutant concentrations at sampling points, or indeed from within layers of similar appearance, show heterogeneous nature of contaminant distribution. The oil percentage in site B is $12.7 \%$ this means that such site existing in continuous region due to high pollutant concentration. From all results we can conclude that the processes of adsorption-desorption play important roles in controlling the migration rate as well as concentration distributions. These processes tend to retard the rate of contaminant migration and act as mechanisms to reduce concentrations.

3.2. Effect of Soil Heterogeneity versus Pollutant Extraction. First lab model (Figure 4) that simulates injection well was used for treatment of all representative polluted samples sites (A, B, C, and D). Results of treatment site A and site $B$ are given in Tables 3 and 4, respectively. The data indicated that only those sites are completely fulfilled and take action towered treatment by injection well simulated lab model. This can be attributed to that the sample from site A is loamy sand, while sample from site B are sand, thereby these types of soil are suitable to treated in site (in situ) during injection and subsequently extraction wells. Our conclusion is identical with Okx and Stein [23] who stated that it's possible to treatment the polluted soil from gravel to fine sand by in situ methods. On the other hand they confirmed the impossibility of in situ treatment for soil samples from sites $\mathrm{C}$ and $\mathrm{D}$ because their analysis indicated that they classified to Loam and clay loam types. To solve this problem the author suggest to go behind Boelsma et al. [24] who used Figure 6 to discussed how far the pressurized liquid extraction can be applied with different soil texture and they mentioned that its suitable to use pressurized liquid extraction technology for sandy clay, sandy clay loam, sandy loam, loamy sand, and sand, and they represented by shaded areas at which pressurized liquid extraction is typically 
TABLE 3: Results of soil treatment from site A.

\begin{tabular}{lcccc}
\hline Flushing cycles & $\begin{array}{c}\text { Pulsing time from zero-2-zero } \\
\text { bar (minute) }\end{array}$ & $\begin{array}{c}\left(m_{o R}\right) \text { original weight } \\
(\mathrm{g} / \mathrm{kg})\end{array}$ & $\begin{array}{c}\left(m_{0}\right) \text { amount of oil removed } \\
(\mathrm{g} / \mathrm{kg})\end{array}$ & $\begin{array}{c}\text { \% of oil extracted } \\
\text { 3\% NPEO } 9 \text { + first air pulse }\end{array}$ \\
Water + second air pulse & 91 & 25.5 & 9.1 & 3.39 \\
Water + third air pulse & 80 & 25.5 & 2.01 & 32.90 \\
Water + fourth air pulse & 60 & 25.5 & 1.55 & 7.89 \\
Water + fifth air pulse & 51 & 25.5 & 0.95 & 6.08 \\
Water + sixth air pulse & 51 & 25.5 & 0.91 & 3.73 \\
Water + seventh air pulse & 51 & 25.5 & 0.87 & 3.57 \\
\hline Total results of site A & 51 & 25.5 & 23.78 & 3.41 \\
\hline
\end{tabular}

TABLE 4: Results of soil treatment from site B.

\begin{tabular}{|c|c|c|c|c|}
\hline Flushing cycles & $\begin{array}{l}\text { Pulsing time from zero-2-zero bar } \\
\text { (minute) }\end{array}$ & $\begin{array}{c}\left(m_{o R}\right) \text { original weight } \\
(\mathrm{g} / \mathrm{kg})\end{array}$ & $\begin{array}{l}\left(m_{o}\right) \text { amount of oil removed } \\
(\mathrm{g} / \mathrm{kg})\end{array}$ & $\begin{array}{l}\% \text { of oil } \\
\text { extracted }\end{array}$ \\
\hline & \multicolumn{4}{|c|}{ First group set } \\
\hline $3 \% \mathrm{NPEO}_{9}+$ first air pulse & 25 & 127.05 & 10.72 & 8.44 \\
\hline Water + second air pulse & 17 & 127.05 & 5.15 & 4.05 \\
\hline Water + third air pulse & 14 & 127.05 & 4.33 & 3.41 \\
\hline Water + fourth air pulse & 10 & 127.05 & 4.02 & 3.16 \\
\hline Water + fifth air pulse & 9 & 127.05 & 3.28 & 2.58 \\
\hline Water + sixth air pulse & 8 & 127.05 & 3.05 & 2.40 \\
\hline Water + seventh air pulse & 8 & 127.05 & 2.98 & 2.35 \\
\hline \multirow[t]{2}{*}{ Sum of first group set } & 91 & 127.05 & 33.53 & 26.39 \\
\hline & \multicolumn{4}{|c|}{ Second group set } \\
\hline $3 \% \mathrm{NPEO}_{9}+$ second air pulse & 21 & 127.05 & 12.66 & 9.96 \\
\hline Water + eighth air pulse & 12 & 127.05 & 6.08 & 4.79 \\
\hline Water + ninth air pulse & 12 & 127.05 & 5.54 & 4.36 \\
\hline Water + tenth air pulse & 10 & 127.05 & 5.22 & 4.11 \\
\hline Water + eleventh air pulse & 10 & 127.05 & 5.19 & 4.09 \\
\hline Water + twelfth air pulse & 10 & 127.05 & 5.03 & 3.96 \\
\hline \multirow[t]{2}{*}{ Sum of second group set } & 75 & 127.05 & 34.69 & 27.30 \\
\hline & \multicolumn{4}{|c|}{ Third group set } \\
\hline $3 \% \mathrm{NPEO}_{9}+$ third air pulse & 35 & 127.05 & 25.53 & 20.09 \\
\hline Water + thirteenth air pulse & 3 & 127.05 & 3.12 & 2.46 \\
\hline Water + fourteenth air pulse & 2 & 127.05 & 3.04 & 2.39 \\
\hline Water + fifteenth air pulse & 2 & 127.05 & 2.88 & 2.27 \\
\hline Water + sixteenth air pulse & 1.45 & 127.05 & 2.61 & 2.05 \\
\hline Water + seventeenth air pulse & 1.45 & 127.05 & 2.99 & 2.35 \\
\hline Water + eighteenth air pulse & 1.45 & 127.05 & 2.5 & 1.97 \\
\hline Water + nineteenth air pulse & 1.45 & 127.05 & 1.44 & 1.13 \\
\hline Water + twentieth air pulse & 1.45 & 127.05 & 1.39 & 1.09 \\
\hline Water + twenty-one air pulse & 1.45 & 127.05 & 1.3 & 1.023 \\
\hline Water + twenty-two air pulse & 1.45 & 127.05 & 1.26 & 0.99 \\
\hline Water + twenty-three air pulse & 1.45 & 127.05 & 1.13 & 0.89 \\
\hline Water + twenty-four air pulse & 1.45 & 127.05 & 0.98 & 0.77 \\
\hline Water + twenty-five air pulse & 1.45 & 127.05 & 0.59 & 0.46 \\
\hline Sum of third group set & 56.5 & 127.05 & 50.76 & 39.95 \\
\hline Total results of site (B) & 222.5 & 127.05 & 118.98 & 93.65 \\
\hline
\end{tabular}




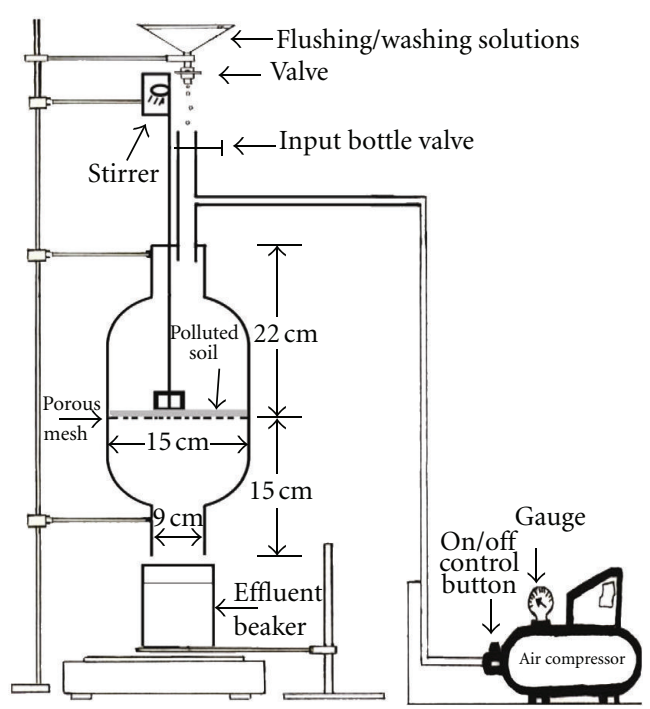

(a)

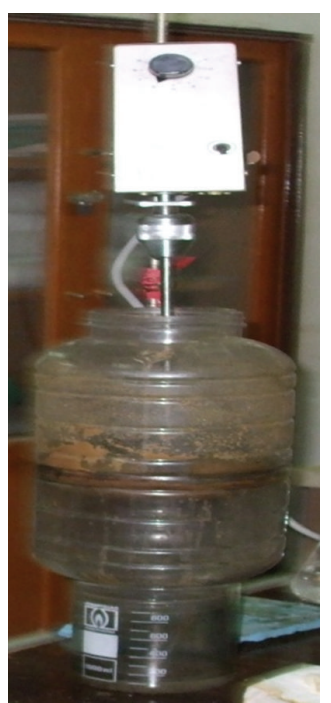

(b)

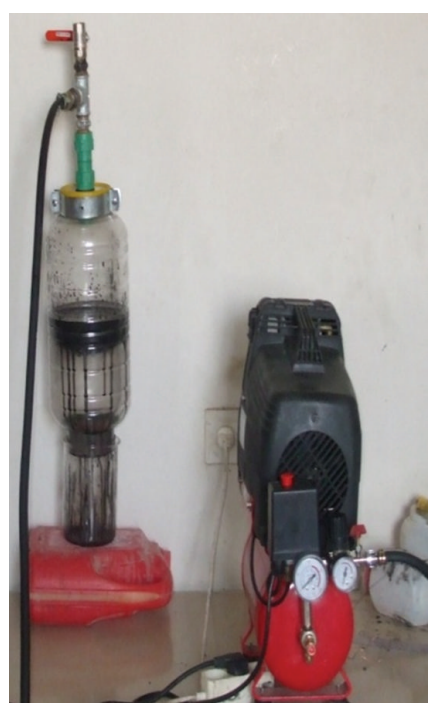

(c)

FIgURE 5: The laboratory experimental model simulates treatment tank.

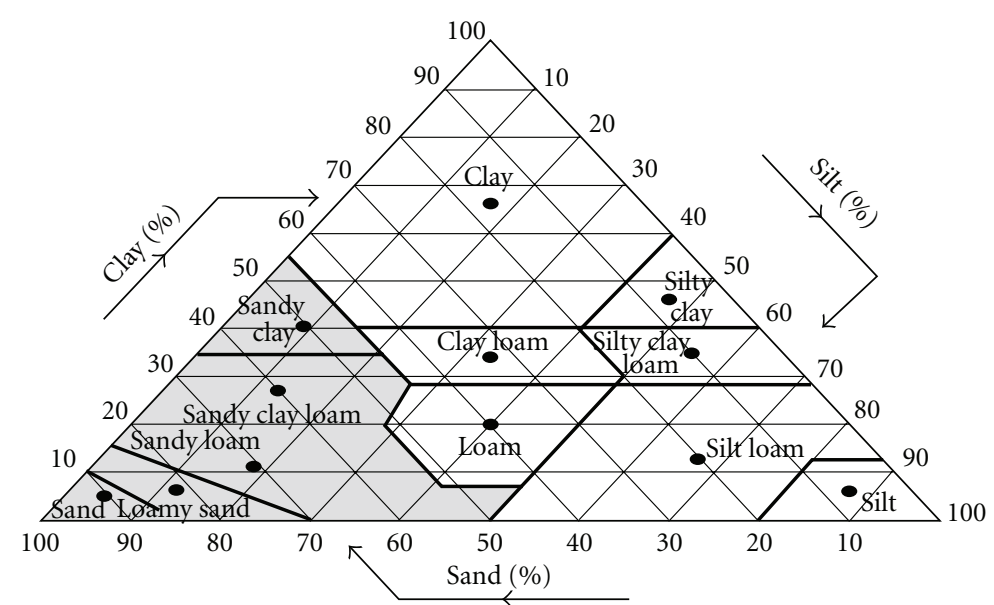

Figure 6: Triangular diagram illustrate the soil texture classification [37].

effective. Therefore, the pressurized liquids technique that was used in current study is considered. Grain size analyses of the samples in current study have been determined using the standard sieving $(>2-<0.004 \mathrm{~mm})$, the results of grain size distribution of the current samples (A-D) are represented in histograms Figure 7. The grain size values reveal that contaminated soil samples that treatment by pressurized liquid extraction (i.e., use of injection solutions) are represent different soil type. These soils are loamy sand, sand, loam and clay loam, for the site A, B, C, and D, respectively. Soil heterogeneity plays a major role in controlling the concentration of contaminants extracted from the contaminated soil. It was also found that the efficiency of remediation depended on the type of the soil and it was much higher for the sand than for the clay soil. This difference can be explained by much looser structure of the soil particulates in the sandy soil and much higher stickiness and plasticity of clay [25]. Clay soil is plastic, consisting mainly of hydrous silicate of aluminum. At the microscopic level, clay is composed of fine particles (diameter $<2 \mu \mathrm{m}$ ), adhering easily to one another [2]. The effect of pressurized liquid extraction on the removal of waste oil are calculated according to Couto et al. [26] and expressed as in (1),

$$
\eta(\%)=\frac{m_{o}}{m_{o R}} \times 100,
$$

where $(\eta)$ is a remediation efficiency at any time, $m_{o}$ is the total amount of oil removed by the remediation fluids in a given period of time, and $m_{O R}$ is the original mass of oil in the soil.

3.3. In Situ Methods for Treatment of Contaminated Soils. The representative sample from site A was found to be loamy sand soil texture and containing $2.55 \%(25.50 \mathrm{gram} / \mathrm{kg})$ waste lubricant oil. The results in Table 3 reveal that, the percentage of removed oil is significantly increased with decreasing air pulsing time. That is, the first air pulse removed out $35.86 \%$ of waste lubricant oil recorded after 91 minutes and that 
TABLE 5: Comparison between treatment conditions related to site A and site B samples.

\begin{tabular}{lccccc}
\hline Sample & No. of $\mathrm{NPEO}_{9}$ flushing cycles & No. of water washing cycles & $\begin{array}{c}\text { Total flushing duration } \\
\text { (minute) }\end{array}$ & $\begin{array}{c}\text { Total washing duration } \\
\text { (minute) }\end{array}$ & $\begin{array}{c}\text { Mud (silt + clay) } \\
(\%)\end{array}$ \\
\hline Site A & 1 & 6 & 91 & 344 & 19 \\
Site B & 3 & 24 & 81 & 141.5 & 0 \\
\hline
\end{tabular}

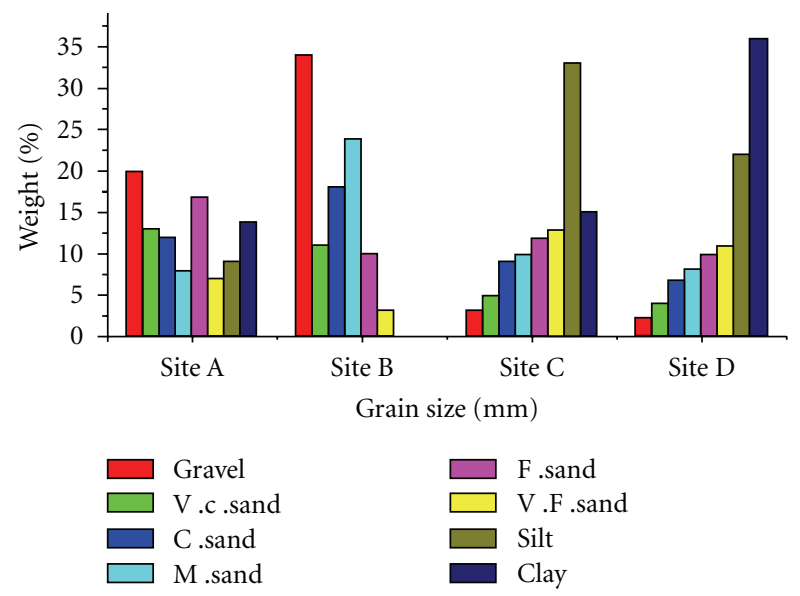

Figure 7: Histogram illustrates the grain size distribution of the studied polluted samples.

time is decreased to 51 minutes beginning from the fourth washing cycle and fixed at that value till the seventh run is finished.

Also, it is found from the first surfactant solution run to the sixth water washing run the time of pulsed emerge nearly decrease to half. Such drastic increase in pressure time drop is attributed to decrease in aqueous phase, which results from cleaning or opening of air channels [27, 28].

The waste lubricant oil concentrations in site B is $12.70 \%$ $(127.05 \mathrm{gram} / \mathrm{kg})$ and is classified as soil sand texture as given in Table 2. The oil removing from site B is carried out using injection well-simulated lab model and is divided to main three air-flushing cycles with $3 \%$ surfactant solution followed by different water washing cycles runs, so the total washing water cycles runs reached to twenty-five. The results in Table 4 reveal that at the first group $8.43 \%$ of oil was removed after surfactant flushing and that values was decreased to $3.08 \%$ after the sixth water run was finished, that is, till the emulsion created during surfactant flushing have been completely push out. On the other hand the total waste oil removal from the first flushing group set is $29.82 \%$ recorded after surfactant flushing followed by six water washing cycle and at total time equal 91 minute.

This result is not satisfied due to the degree of saturation and age of waste oil in this sample not solubilized yet. This deduction matched with Zhou and Rhue [29] they confirmed that, the solubility of hydrocarbons depends on the type and quantity of surfactant, and the age of contamination. Beck et al. [30] emphasized the biphasic nature of contaminant release from the solid phase; where compounds are not degraded or lost fairly quickly from soil, their chemical and biological availability decreases rapidly over periods of minutes to hours, then slowly over periods of weeks to months through sorption and diffusion processes referred to as "ageing" [31].

In the second flushing set group is carried out on the remaining soil using $300 \mathrm{~mL}$ of $3 \%$ surfactant solution followed by five water washing cycles and the results are given in Table 4. The results reveal that, the percentage of removed oil was $9.96 \%$ from residual oil after first surfactant flushing run and decreased to $4.79 \%$ for next run (water washing cycle). The later water washing cycles remove oil out from $4.36 \%$ to $3.96 \%$. On the other hand $27.30 \%$ of residual waste oil after the first treatment run was extracted with total time equal 75 minute. It is clear that the percentage of oil recovery proceed in reverse order with adsorption process (adhesion of oil on the surface of the soil). Sorption has a rapid phase within $48 \mathrm{~h}$ and a slower desorption phase that can take weeks even years [32]. In response, the effort is to quickly recover or cleanup spilled waste lubricant oil both from the ground surface and from subsoil. Reducing of waste lubricant oil concentrations in the soil below those corresponding retention capacities (saturation values) by fast recovery will stop spreading of waste lubricant oil in soil dramatically.

For the third flushing cycle, as revealed in Table 4 the results indicated that $20.09 \%$ was pushed out during this flushing run with air pulse time recorded 35 minutes for emerge. This means that solubility originated coherently with the third flushing solution. Also the time dropped from 35 minute where stable at 1.45 minute from eighteenth to twenty-seven air pulse. Such drastic increase in pressure time drop is attributed to decrease in aqueous phase, which results from cleaning or opening of air channels as mentioned by Clayton [27] andChao et al. [28]. Finally, the total waste lubricant oil recovery of site $\mathrm{B}$ is $93.65 \%$.

\subsection{Effect of Treatment Time and Soil Heterogeneity-Related} Issues. The results in Table 5 reveal that the total flushing durations are 91 and $81 \mathrm{~min}$, total washing durations are 344 and 141.5 mins for sites A and B, respectively. The high flushing and washing duration time can be attributed to the high percentage of mud in site A over site B, that is, $19 \%$ and zero, respectively. This means that the performance of surfactant flushing/water washing can be adversely affected by geologic heterogeneity, because soil heterogeneities can cause poor-pressurized liquids sweep of the area targeted for remediation, although heterogeneity may reduce effectiveness. With increasing silt and clay content in polluted soil, the corresponding treatment duration time has been directly increased as showing in Figures 8 and 9. Thus, pressurized liquid technologies work in heterogeneous media, but cleanup times will be longer and more difficult to estimate than for similar systems in more homogeneous media. 
TABLE 6: Results of soil treatment form site (C).

\begin{tabular}{lcccc}
\hline Flushing cycles & $\begin{array}{c}\text { Pulsing time from zero-2-zero bar } \\
(\text { minute })\end{array}$ & $\begin{array}{c}\left(m_{o R}\right) \\
(\mathrm{g} / \mathrm{kg})\end{array}$ & $\begin{array}{c}\left(m_{0}\right) \text { amount of oil removed } \\
(\mathrm{g} / \mathrm{kg})\end{array}$ & $\begin{array}{c}\text { \% of oil extracted } \\
\text { 3\% } \mathrm{NPEO}_{9}+\text { first air pulse }\end{array}$ \\
Water + second air pulse & 2 & 58.08 & 59.36 & 84.99 \\
\hline Total results of site $(\mathrm{C})$ & 2 & 58.08 & 5.82 & 13.46 \\
\hline
\end{tabular}

In general, sites having high clay or silt content in soils are not typical in situ candidates for this technology [33]. In an environment with low permeability layers or units interspersed with higher permeability zones, fluids preferentially flow through higher permeability zones, thereby reducing the performance of the chemical injected in the lower permeability zones. In general, high permeability soil is favored for pressurized liquids since numerous pore volumes can be passed through the contaminated area. Layered systems are difficult to remediate due to limited contact in less permeable areas. Also, fractured rock is extremely challenging due to the flow complexity in the fractured media. However, these challenges are relevant for all remediation technologies. Comparisons under the same conditions in these difficult media should be performed determine if surfactant flushing is able to remove contaminants faster than other technologies [34].

\subsection{Ex Situ Methods for Treatment of Fine-Grained Contami-} nated Soils. As mentioned before and illustrated in Figure 6, both of sites $\mathrm{C}$ and $\mathrm{D}$ characterized by loam and clay loam could not able to applying the injection well simulation lab model (in situ treatment), therefore another lab model has been used and known by simulates treatment tank (ex situ treatment) and its outline is given before in Figure 5. The (ex situ treatment), that is, sediment relocation has been used internationally as an operational response to treat oil spills throughout the world [35]. Ex situ involves the excavation of contaminated soil for treatment in aboveground. The soil may be transported to special facilities where remediation may be carried out in special reactors or vessels, which are specially designed for this purpose (ex situ or in tank method) [36]. An example of this process is the washing of heavily polluted soils in special tanks. The polluted soil may also be transported and spread on a surface prepared to prevent the spread of contamination in lateral and vertical directions. Beds arranged in this way form the socalled prepared beds, upon which the remediation process will take place. This method is especially suitable for soils contaminated with oil products.

Ex situ treatment have been applied for treatment polluted soil tacking from site $\mathrm{C}$ that containing original weight $58.08 \mathrm{~g} / \mathrm{kg}$ waste lubricant oil and characterized by loam soil texture. The results in Table 6 reveal that the percentage of removed oil is $84.99 \%$ after first flushing cycle using 3\% nonionic surfactant solution. This high percentage of oil removal has been realized under low pressure equal 1.5 bar and at very short time duration about 2 minutes. By the same manner at the same time and pressure the second air injection (water washing cycle) was applied to push out

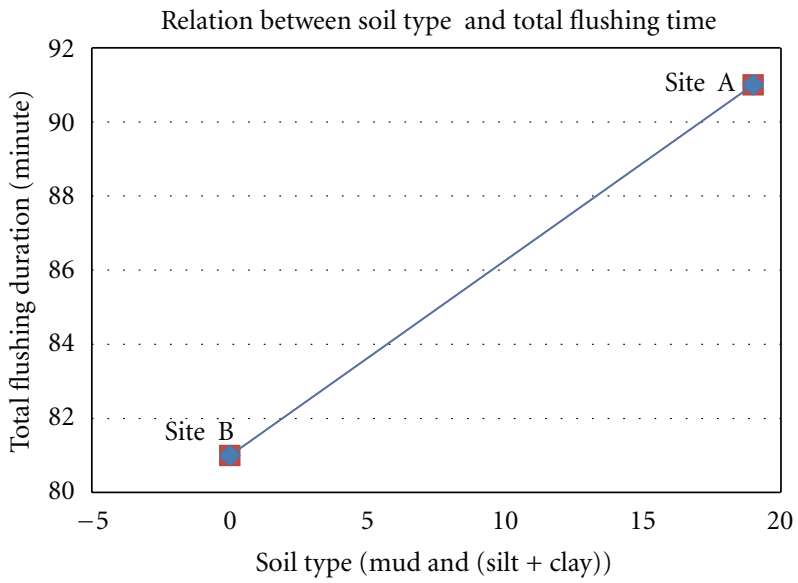

Figure 8: The relationship between mud $\%$ and surfactant flushing time (minute).

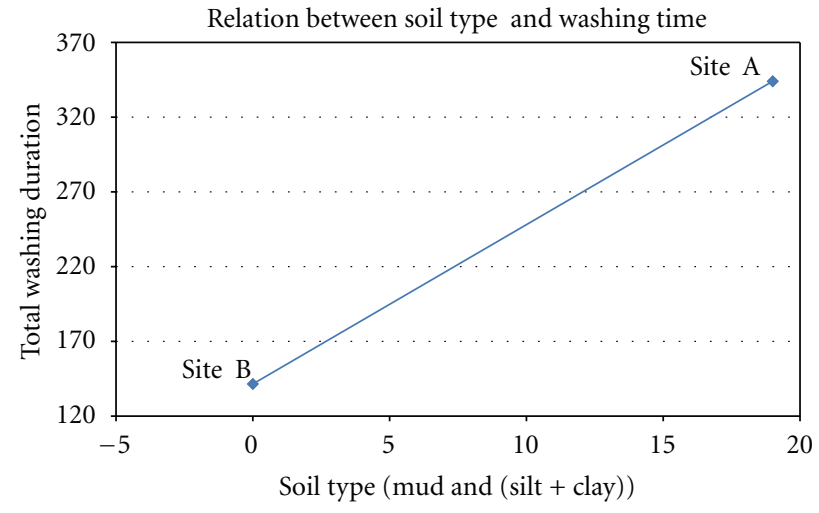

FIGURE 9: The relationship between mud \% and water washing times (minute).

$13.46 \%$ from residual oil. So the total percentage of extracted waste lubricant oil rises to $98.45 \%$. Both flushing and washing cycles follow on stir periods to wash out very fine grains which subjected to measure the grain size diameter via petrographic microscope and the photomicrograph are given in Figure 10. Such figure represent photomicrograph of higher clay content and polluted oil patches in loam soil of site $\mathrm{C}$ sample are ranged from $0.063 \mathrm{~mm}$ to less than $5 \mu \mathrm{m}$. The same treatment manner has been applied to treatment of site D sample that containing $42.73 \mathrm{~g} / \mathrm{kg}$ original weight wastes lubricant oil and characterized as clay loam soil texture. The results in Table 7 reveal that the percentage of removed oil is $44.35 \%$ after first flushing cycle using $3 \%$ nonionic surfactant solution under pressure of $1.5 \mathrm{bar}$ and duration time 2 minutes. The percentage of oil removal in the second air injection (water washing 
TABLE 7: Results of soil treatment from site D.

\begin{tabular}{|c|c|c|c|c|}
\hline Flushing cycles & $\begin{array}{l}\text { Pulsing time from zero-2-zero bar } \\
\text { (minute) }\end{array}$ & $\begin{array}{c}\left(m_{o R}\right) \text { original weight } \\
(\mathrm{g} / \mathrm{kg})\end{array}$ & $\begin{array}{c}\left(m_{o}\right) \text { amount of oil removed } \\
(\mathrm{g} / \mathrm{kg})\end{array}$ & $\%$ of oil extracted \\
\hline $3 \% \mathrm{NPEO}_{9}+$ first air pulse & 2 & 42.73 & 18.95 & 44.35 \\
\hline Water + second air pulse & 2 & 42.73 & 11.78 & 27.57 \\
\hline Total results of site (D) & 4 & 42.73 & 30.73 & 71.92 \\
\hline
\end{tabular}

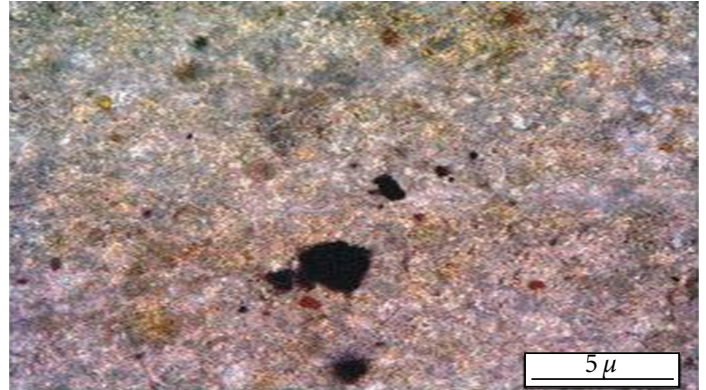

Figure 10: Photomicrograph show the higher clay content and oil pollution patches in loam soil of site $\mathrm{C}$ sample.

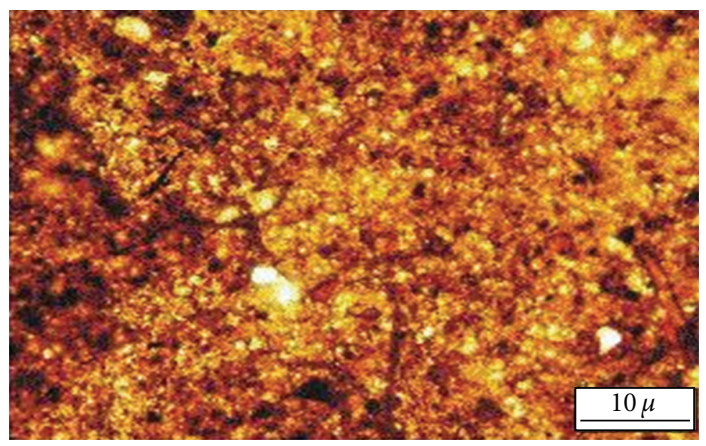

FIgURE 11: Photomicrograph shows the higher clay content and a lot of oil patches in clay loam soil of site D sample.

cycle) is $27.57 \%$ from residual oil. So the total percentage of extracted waste lubricant oil rises to $71.92 \%$. Both flushing and washing cycles follow on stir periods to wash out very fine grains and after that the sample was subjected to measure the grain size diameter via petrographic microscope and the photomicrograph are given in Figure 11. Such figure represent the that the photomicrograph of higher clay content and oil pollution patches in clay loam soil of site (D) sample are ranged from $0.063 \mathrm{~mm}$ to less than $10 \mu \mathrm{m}$.

The efficiency of detoxification (i.e., waste lubricant oil removal) rate and extent for a waste is a function of soil type arises in Tables 6 and 7. The data reveals that the loam soil give satisfied results, where clay loam gives worse results, this because of its higher stickiness and plasticity. Also clay loam soil (site D) contains swelling clay that reduces permeability and emulsion formation, as mentioned by Kujawski et al. [2]. The swelling clay results from absorption of aqueous solution (water) which causes loss of surfactant due to soil sorption, sorbed surfactant molecules of the solids also increase contaminant sorption. This phenomenon was observed for 2-methynaphthalene [38], PCP [39], and other compounds. Our results are in agreement with Kibbey and Hayes [40] they mentioned that loss of aqueous surfactant due to soil sorption may significantly increase the surfactant doses required to enhance site remediation.

Generally, in the ex situ process the removal efficiency can be better controlled and the cleanup period is relatively short. This accomplished during soil treatment process of site $\mathrm{C}$ and site $\mathrm{D}$ samples, which carry out through separates fine soil (clay and silt) from coarse soil (sand and gravel). Since hydrocarbon contaminants tend to bind and sorb to smaller soil particles (primarily clay and silt), separating the smaller soil particles from the larger ones reduces the volume of contaminated soil. Soil washing depend on clay and silt separation processalso recommended by Riser-Roberts [41]. Also soil treatment in aboveground reactors allows a greater process control that is generally impossible with in situ techniques. Mass transfer of organic compounds (desorption from solids) is greatly increased in ex situ remediation process because its more applicable to finegrained, low permeability soils which are not amenable to in situ techniques. In general, ex situ remediation is favored over in situ techniques for heavily contaminated soil and relatively localized and shallow contamination [42]. Ex situ soil washing is commonly used for treating contaminated soils by separating the most contaminated fraction of the soil for disposal. Surfactant enhanced ex situ soil washing can offer the convenience, efficiency and economy desirable for innovative and alternative soil washing technologies. However, surfactant selection guide-lines are needed to be evaluated in ex situ soil washing is important for the soil remediation industry [43].

On the other hand, RAAG [44], Chu and Chan [45] reported that the smaller volume of soil, that contains the majority of clay and silt particles, can be further treated by other methods (such as bioremediation) or disposed in accordance with environmental regulations, whereas to clean the larger volume of soil is considered to be nontoxic and can be used as backfill.

\section{Conclusions}

Soil remediation by surfactant solutions flushing is a common practice successfully done in a pilot-scale and fieldscale studies, where the apparent contaminant solubility in surfactant solutions can be hundreds to thousands times higher than its water solubility if a traditional pump and treat method is applied. This example of the use of a treatment train for creosote-contaminated soil, and if applied either in suit or ex situ were involves: (1) free product removal as it possible using a pumping system, (2) flushing with 
surfactants and washing by water using air-sparging technology as distribution system and to insure kinetic energy for emulsion formation and moving, and (3) biodegradation of the residual contamination, by air sparging or air stripping.

\section{Studied Soil Reach}

The research work carried out throughout this study at Water laboratory Geology Department, El-Minia University, Faculty of Science, El-Minia, Egypt, and divided into two main parts: the first part is a laboratory study started since April 2009 ending July 2009, in this respect a simulated lab model is designed and packed with artificial polluted soils submerged with nonionic surfactant in presence of air sparging as mentioned in experimental part, where the second part is started in August 2009 ending in January 2010 by applying the results of the first part on some rails-polluted areas located in El-Minia, the results are not mentioned in this article, as well as they are not published or sent for publication till now.

\section{Acknowledgments}

This work was supported by a grant from Egyptian Petroleum Research Institute, El-Minia University, Faculty of Science, and Geology Department and Engineering Petrotread Co.

\section{References}

[1] J. H. Harwell, D. A. Sabatini, and R. C. Knox, "Surfactants for ground water remediation," Colloids and Surfaces A, vol. 151, no. 1-2, pp. 255-268, 1999.

[2] W. Kujawski, I. Koter, and S. Koter, "Membrane-assisted removal of hydrocarbons from contaminated soils-laboratory test results," Desalination, vol. 241, no. 1-3, pp. 218-226, 2009.

[3] B. K. Gogoi, N. N. Dutta, P. Goswami, and T. R. K. Mohan, "A case study of bioremediation of petroleum-hydrocarbon contaminated soil at a crude oil spill site," Advances in Environmental Research, vol. 7, no. 4, pp. 767-782, 2003.

[4] C. W. Fetter, Contaminant Hydrogeology, Prentice-Hall, Upper Saddle River, NJ, USA, 2nd edition, 1999.

[5] J. F. Pankow and J. A. Cherry, Dense Chlorinated Solvents and other DNAPLs in Ground-Water, Waterloo Press, Portland, Ore, USA, 1996.

[6] R. A. Mackay, in Nonionic Surfactants: Physical Chemistry, M. J. Schick, Ed., vol. 23 of Surfactant Science Series, pp. 297-367, Marcel Dekker, New York, NY, USA, 1985.

[7] R. N. Yong, A. M. O. Mohamed, and B. P. Warkentin, Principles of Contaminant Transport in Soils, Elsevier, Amsterdam, The Netherlands, 1992.

[8] A. Wild, Soils and the Environment: An Introduction, Cambridge University Press, 1993.

[9] J. W. Mercer and R. M. Cohen, "A review of immiscible fluids in the subsurface: properties, models, characterization and remediation," Journal of Contaminant Hydrology, vol. 6, no. 2, pp. 107-163, 1990.

[10] Y. J. Tsai, F. C. Chou, and S. J. Cheng, "Using tracer technique to study the flow behavior of surfactant foam," Journal of Hazardous Materials, vol. 166, no. 2-3, pp. 1232-1237, 2009.
[11] D. Feng and C. Aldrich, "Sonochemical treatment of simulated soil contaminated with diesel," Advances in Environmental Research, vol. 4, no. 2, pp. 103-112, 2000.

[12] R. O. Gilbert, Statistical Methods for Environmental Pollution Monitoring, Van Nostrand Reinhold, New York, NY, USA, 1987.

[13] R. J. Jessen, Statistical Survey Techniques, John Wiley \& Sons, New York, NY, USA, 1978.

[14] X. Zhang, G. H. Huang, Q. Lin, and H. Yu, "Petroleumcontaminated groundwater remediation systems design: a data envelopment analysis based approach," Expert Systems with Applications, vol. 36, no. 3, pp. 5666-5672, 2009.

[15] M. Vukovic and A. Soro, Determination of Hydraulic Conductivity of Porous Media from Grain-Size Composition, Water Resources, Littleton, Colo, USA, 1992.

[16] S. K. Chaerun, K. Tazaki, R. Asada, and K. Kogure, "Bioremediation of coastal areas 5 years after the Nakhodka oil spill in the Sea of Japan: isolation and characterization of hydrocarbon-degrading bacteria," Environment International, vol. 30, no. 7, pp. 911-922, 2004.

[17] C. K. Ahn, Y. M. Kim, S. H. Woo, and J. M. Park, "Soil washing using various nonionic surfactants and their recovery by selective adsorption with activated carbon," Journal of Hazardous Materials, vol. 154, no. 1-3, pp. 153-160, 2008.

[18] RIGW, Feasibility of Vertical Drainage in the Nile Valley, Minia pilot Area, Ministry of Irrigation, Cairo, Egypt, 1986.

[19] X. Yang, D. Beckmann, S. Fiorenza, and C. Niedermeier, "Field study of pulsed air sparging for remediation of petroleum hydrocarbon contaminated soil and groundwater," Environmental Science and Technology, vol. 39, no. 18, pp. 7279-7286, 2005.

[20] R. Khalladi, O. Benhabiles, F. Bentahar, and N. MoulaiMostefa, "Surfactant remediation of diesel fuel polluted soil," Journal of Hazardous Materials, vol. 164, no. 2-3, pp. 11791184, 2009.

[21] S. Marek, K. Martin, M. Martina, and R. Robert, "Soil flushing by surfactant solution: pilot-scale demonstration of complete technology," Journal of Hazardous Materials, vol. 163, no. 1, pp. 410-417, 2009.

[22] HMWMD, Management Standards for Used Oil Transporters Guidance Document, Hazardous Materials and Waste Management Division, Colorado Department of Public Health and Environment, 1st edition, 2005, http://www.cdphe.state .co.us/hm/oilgen.pdf.

[23] J. P. Okx and A. Stein, "An expert support model for in situ soil remediation," Water, Air, and Soil Pollution, vol. 118, no. 3-4, pp. 357-375, 2000.

[24] F. . Boelsma, E. C. L. Marnette, C. G. J. M. Pijls, C. C. D. F. van Ree, and K. Vreeken, In Situ Air Sparging, A Technical Guide, Geodelft Environmental, Delft, The Netherlands, 1999.

[25] A. G. Link, "Textural classification of sediments," Soil Texture Classifications, Sedimentology, vol. 7, pp. 249-254, 1966.

[26] H. J. B. Couto, G. Massarani, E. C. Biscaia, and G. L. Sant'Anna, "Remediation of sandy soils using surfactant solutions and foams," Journal of Hazardous Materials, vol. 164, no. 2-3, pp. 1325-1334, 2009.

[27] W. S. Clayton, "A field and laboratory investigation of air fingering during air sparging," Ground Water Monitoring and Remediation, vol. 18, no. 3, pp. 134-145, 1998.

[28] K. P. Chao, S. K. Ong, and A. Protopapas, "Water-to-air mass transfer of VOCs: laboratory-scale air sparging system," Journal of Environmental Engineering, vol. 124, no. 11, pp. 1054-1060, 1998. 
[29] M. Zhou and R. D. Rhue, "Screening commercial surfactants suitable for remediating DNAPL source zones by solubilization," Environmental Science and Technology, vol. 34, no. 10, pp. 1985-1990, 2000.

[30] A. J. Beck, S. C. Wilson, R. E. Alcock, and K. C. Jones, "Kinetic constraints on the loss of organic chemicals from contaminated soils: implications for soil-quality limits," Critical Reviews in Environmental Science and Technology, vol. 25, no. 1, pp. 1-43, 1995.

[31] K. T. Semple, A. W. J. Morriss, and G. I. Paton, "Bioavailability of hydrophobic organic contaminants in soils: fundamental concepts and techniques for analysis," European Journal of Soil Science, vol. 54, no. 4, pp. 809-818, 2003.

[32] D. M. LaGrega, P. L. Buckingham, and J. C. Evans, in Hazardous Waste ManagementThe Environmental Resources Management Group, P. H. King and R. Elianssen, Ed., Civil Engineering Series, Mc-Graw-Hill, Singapore, 1994.

[33] B. C. Kirtland and C. M. Aelion, "Petroleum mass removal from low permeability sediment using air sparging/soil vapor extraction: impact of continuous or pulsed operation," Journal of Contaminant Hydrology, vol. 41, no. 3-4, pp. 367-383, 2000.

[34] ITRC, Technical and regulatory guidance for surfactant/cosolvent flushing of DNAPL source zones. (Interstate Technology \& Regulatory Council) DNAPL-3, 2003, http://www .itrcweb.org/Documents/DNAPLs-3.pdf.

[35] M. O. Hayes and J. Michel, "Factors determining the longterm persistence of Exxon Valdez oil in gravel beaches," Marine Pollution Bulletin, vol. 38, no. 2, pp. 92-101, 1999.

[36] G. A. Sergy, C. C. Guénette, E. H. Owens, R. C. Prince, and K. Lee, "In-situ treatment of oiled sediment shorelines," Spill Science and Technology Bulletin, vol. 8, no. 3, pp. 237-244, 2003.

[37] D. C. DiGiulio, U.S. EPA Robert S. Kerr Environmental Research Laboratory, personal communication, Ada, Okla, USA, 1989.

[38] Y. P. Chin, K. D. Kimble, and C. Robin Swank, "The sorption of 2-methylnaphthalene by Rossburg Soil in the absence and presence of a nonionic surfactant," Journal of Contaminant Hydrology, vol. 22, no. 1-2, pp. 83-94, 1996.

[39] S. K. Park and A. R. Bielefeldt, "Aqueous chemistry and interactive effects on non-ionic surfactant and pentachlorophenol sorption to soil," Water Research, vol. 37, no. 19, pp. 4663 4672, 2003.

[40] T. C. G. Kibbey and K. F. Hayes, "A multicomponent analysis of the sorption of polydisperse ethoxylated nonionic surfactants to aquifer materials: equilibrium sorption behavior," Environmental Science and Technology, vol. 31, no. 4, pp. 11711177, 1997.

[41] E. Riser-Roberts, Remediation of Petroleum Contaminated Soil: Biological, Physical, and Chemical Processes, Lewis, Boca Raton, Fla, USA, 1998.

[42] W. Admassu and R. A. Korus, "Engineering of bioremediation processes: needs and limitations," in Bioremediation: Principles and Applications, R. L. Crawford and D. L. Crawford, Eds., pp. 13-34, Cambridge University Press, Cambridge, UK, 1996.

[43] S. Deshpande, B. J. Shiau, D. Wade, D. A. Sabatini, and J. H. Harwell, "Surfactant selection for enhancing ex situ soil washing," Water Research, vol. 33, no. 2, pp. 351-360, 1999.

[44] RAAG, Evaluation of Risk Based Corrective Action Model, Remediation Alternative Assessment Group, Memorial University of NewfoundlandNF, St John's, Canada, 2000.

[45] W. Chu and K. H. Chan, "The mechanism of the surfactantaided soil washing system for hydrophobic and partial hydrophobic organics," Science of the Total Environment, vol. 307, no. 1-3, pp. 83-92, 2003. 

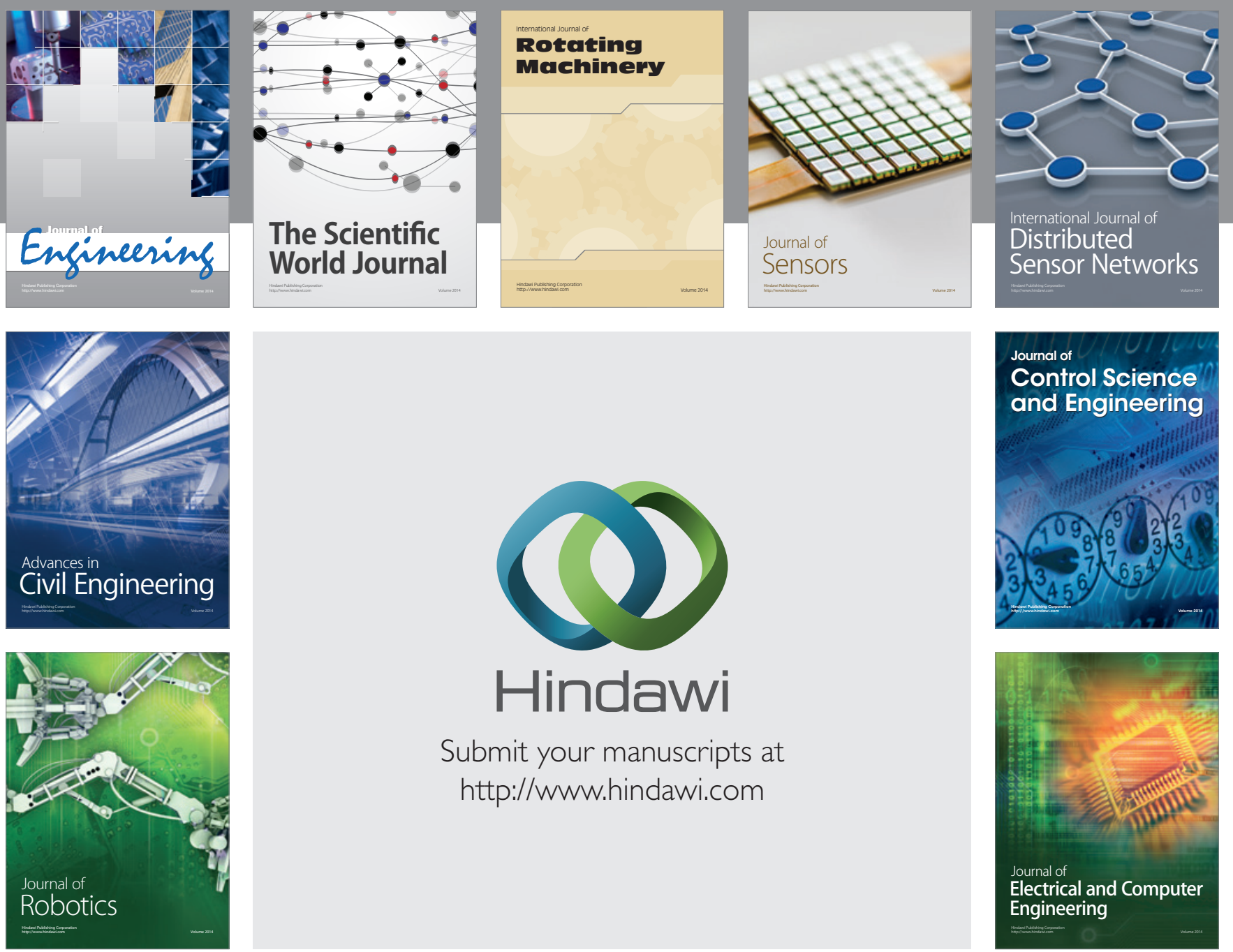

Submit your manuscripts at

http://www.hindawi.com
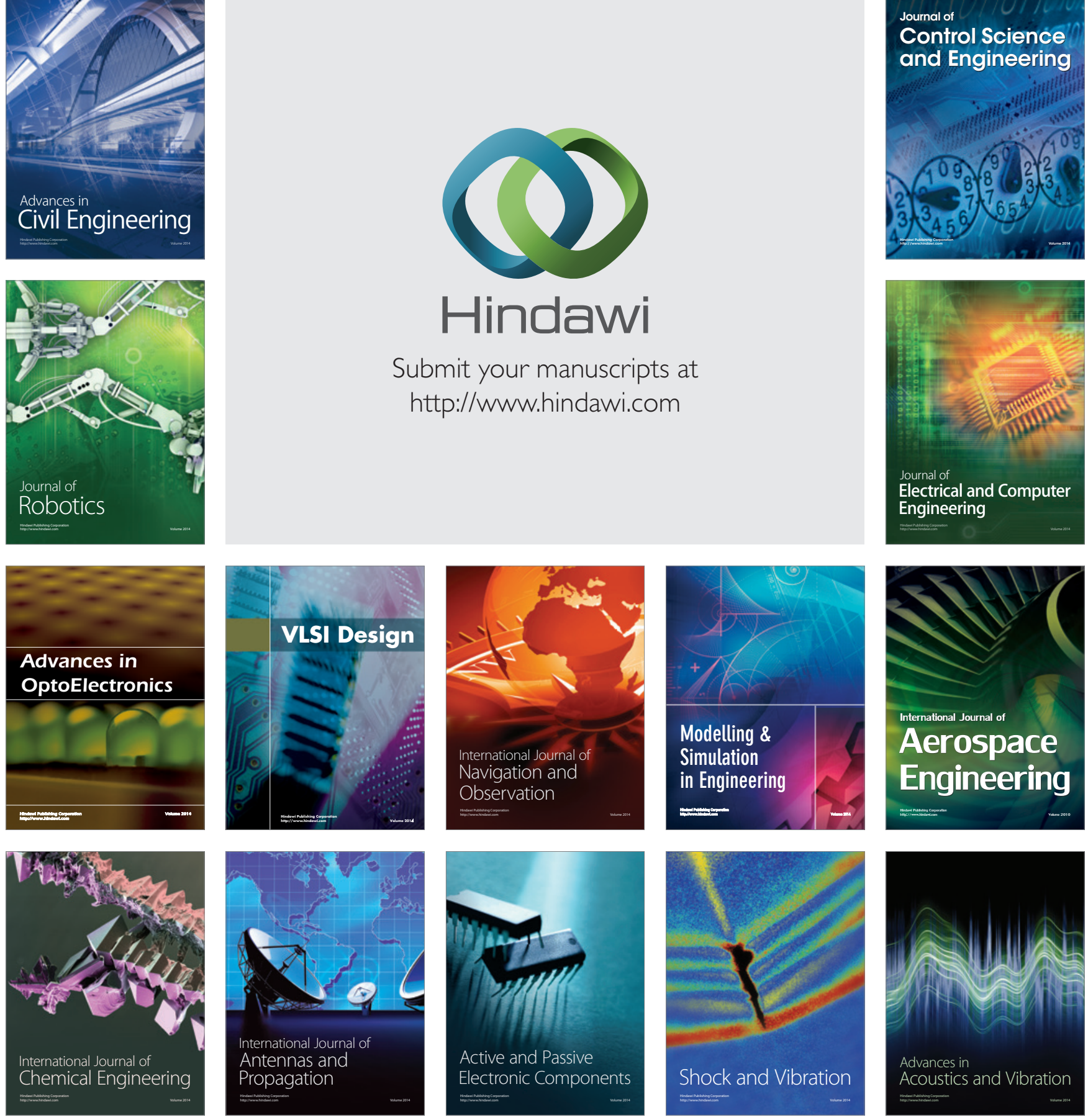